\title{
Risk, Promotive, and Protective Factors in Youth Offending: Results from the Cambridge Study in Delinquent Development
}

\author{
David P. Farrington and Maria M. Ttofi \\ Institute of Criminology, \\ Cambridge University \\ Alex R. Piquero \\ Program in Criminology, \\ University of Texas at Dallas
}

May 2015

Submitted to Journal of Criminal Justice

Corresponding author: David P. Farrington, Cambridge University, Institute of Criminology, Sidgwick Avenue, Cambridge CB3 9DA, UK email: dpf1@cam.ac.uk 


\section{Abstract}

Purpose: The main aim of this research is to investigate risk, promotive, risk-based protective, and interactive protective factors for delinquency.

Methods: The Cambridge Study in Delinquent Development is a prospective longitudinal survey of 411 London males from age 8 onwards. Variables measured at age 8-10 are investigated as predictors of convictions between ages 10 and 18 .

Results: High troublesomeness, a convicted parent, and high daring were important risk factors for delinquency, while low neuroticism and few friends were important promotive factors. The most important interactive effects were: high nonverbal intelligence, high verbal intelligence, high school attainment, and high parental interest in education protected against poor child-rearing; good parental supervision protected against high dishonesty; and high family income protected against a convicted parent.

Conclusions: Developmental and life-course theories of offending should attempt to explain findings on promotive and protective factors. Findings on interactive protective factors suggest particular types of interventions that should be targeted on individuals displaying particular risk factors. 


\section{Introduction}

This article first investigates risk and promotive factors for delinquency in the Cambridge Study in Delinquent Development (CSDD). It then investigates risk-based protective factors and interactive protective factors. Since there is some confusion about the definition of these terms, they are discussed in detail in the next sections.

Risk and protective factors

During the 1990s, there was a revolution in criminology, as the risk factor prevention paradigm became influential (Farrington, 2000). The basic idea of this paradigm is very simple: identify the key risk factors for offending and implement prevention methods designed to counteract them. This paradigm was imported into criminology from public health, where it had been used successfully for many years to tackle illnesses such as cancer and heart disease, by pioneers such as Hawkins and Catalano (1992). The risk factor prevention paradigm links explanation and prevention, links fundamental and applied research, and links scholars, policy makers, and practitioners. Loeber and Farrington (1998) presented a detailed exposition of this paradigm as applied to serious and violent juvenile offenders. Empirical research continues to show that serious, violent, and chronic juvenile offenders have different risk and protective factors than their counterparts and intervention efforts aimed at addressing these factors is critical for reducing recidivism (Baglivio, Jackowski, Greenwald, \& Howell, 2014)

A risk factor is defined as a variable that predicts a high probability of offending. Usually, risk factors are dichotomized. This makes it easy to study interaction effects, to identify persons with multiple risk factors, to specify how outcomes vary with the number of risk factors, and to communicate results to policy-makers and practitioners as well as to researchers (Farrington \& Loeber, 2000). Dichotomization also deals with the problem of nonlinear relationships, does not necessarily result in a decrease in the measured 
strength of associations, and the order of importance of risk factors is usually similar in dichotomous and continuous analyses.

Risk factors are not necessarily causes. (For discussions of the key concepts involved in risk factor research, see Kazdin, Kraemer, Kessler, Kupfer, \& Offord, 1997; Kraemer, Kazdin, Offord, Kessler, Jensen, \& Kupfer, 1997). The most convincing method of establishing causes of offending is to show that changes in a presumed causal factor within individuals are reliably followed by changes in offending within individuals (Farrington, 1988). For example, in the Pittsburgh Youth Study (PYS), which is a prospective longitudinal survey of over 1,500 boys from age 7 to age 30 , changes within individuals in parental supervision, parental reinforcement, and involvement of the boy in family activities predicted within-individual changes in offending (Farrington, Loeber, Yin, \& Anderson, 2002).

Many researchers have discussed the need to study protective factors as well as risk factors, and to strengthen protective factors as well as to reduce risk factors in intervention programs. For example, Pollard, Hawkins, and Arthur (1999) argued that focussing on protective factors and on building resilience of children was a more positive approach, and more attractive to communities, than reducing risk factors, which emphasized deficits and problems. Unfortunately, the term "protective factor" has been used inconsistently. Some researchers have defined a protective factor as a variable that predicts a low probability of offending, or as the "mirror image" of a risk factor (e.g., White, Moffitt, \& Silva, 1989), while other researchers have defined a protective factor as a variable that interacts with a risk factor to nullify its effect (e.g., Rutter, 1985), or as a variable that predicts a low probability of offending among a group at risk (e.g., Werner \& Smith, 1982).

Inspired by Sameroff, Bartko, Baldwin, Baldwin, and Seifer (1998), Loeber, Farrington, Stouthamer-Loeber, and White (2008) proposed that a variable that predicted 
a low probability of offending should be termed a "promotive factor". It might be argued that a promotive factor is just "the other end of the scale" to a risk factor, and therefore that calling a variable both a promotive factor and a risk factor is rather redundant, using two names for the same variable. However, this is not necessarily true, and it depends on whether the variable is linearly or nonlinearly related to offending as we discuss below.

Defining risk, promotive, and protective factors

In order to investigate risk and promotive factors in the PYS, Loeber et al. (2008, Chapter 7) trichotomized variables into the "worst" quarter (e.g., low school achievement), the middle half, and the "best" quarter (e.g., high school achievement). They studied risk factors by comparing the probability of offending in the worst quarter versus the middle half, and they studied promotive factors by comparing the probability of offending in the middle half versus the best quarter. They used the odds ratio $(\mathrm{OR})$ as the main measure of strength of effect; an OR of 2.0 or greater indicates quite a strong effect (Cohen, 1996).

If a predictor is linearly related to delinquency, so that the percent delinquent is low in the best quarter and high in the worst quarter, that variable could be regarded as both a risk factor and a promotive factor. However, if the percent delinquent is high in the worst quarter but not low in the best quarter, that variable could be regarded only as a risk factor. Conversely, if the percent delinquent is low in the best quarter but not high in the worst quarter, that variable could be regarded only as a promotive factor. Most studies of the predictors of delinquency label them as "risk factors" but researchers should distinguish these three types of relationships.

Loeber et al. (2008, Chapter 7) systematically investigated relationships between predictor variables and two outcomes (violence and serious theft) and found many examples of pure risk factors and pure promotive factors. As an example, Figure 1 shows two results from the prediction of violence in early adulthood (ages 20-25) by variables measured in early adolescence (ages 13-15) in the oldest Pittsburgh cohort of 500 males. 
School achievement was clearly a promotive factor. The percent of boys who were violent was $8 \%$ (high achievement), $21 \%$ (middle), and $21 \%$ (low achievement), with a promotive

OR of 2.9 and a risk OR of 1.0. Here, high achievement is the promotive category and low achievement is the risk category. In contrast, peer delinquency was clearly a risk factor. The percent of boys who were violent was $9 \%$ (low delinquent peers), $11 \%$ (middle), and $40 \%$ (high delinquent peers), with a risk OR of 5.5 and a promotive OR of 1.2.

\section{Figure 1 about here}

In the PYS, Loeber et al. (2008, Chapter 7) were surprised to find that several variables previously labeled as risk factors instead operated as promotive factors, especially high academic achievement, an older mother, low ADHD (attention deficithyperactivity disorder), low physical punishment, good parental supervision, high involvement in family activities, and living in a good neighborhood. In contrast, peer delinquency and large family size operated as risk factors, and several variables had linear relationships with violence and serious theft. Promotive factors were more common at younger ages.

As mentioned, a protective factor is a variable that interacts with a risk factor to nullify its effect, or alternatively a variable that predicts a low probability of offending among a group at risk. We will term the former "an interactive protective factor" and the latter "a risk-based protective factor". There have been fewer studies of interaction effects than of protective effects in a high risk group. An interactive protective factor is defined as follows: When the protective factor is present, the probability of offending does not increase in the presence of the risk factor; when the protective factor is absent, the probability of offending does increase in the presence of the risk factor. An alternative way of interpreting this interaction effect is as follows: When a risk factor is present, the probability of offending decreases in the presence of a protective factor; when a risk factor 
is absent, the probability of offending does not decrease in the presence of a protective factor.

\section{Methods}

This article analyzes data collected in the Cambridge Study in Delinquent Development (CSDD), which is a prospective longitudinal survey of 411 South London males (see Farrington et al., 2006; Farrington, Coid, \& West, 2009a; Farrington, Piquero, \& Jennings, 2013; Piquero, Farrington, \& Blumstein, 2007). These males were chosen because they were in the second forms of six state primary schools in a working-class area of London. They were not a sample but a complete population of boys of that age in those schools at that time. These males were first assessed at age 8-9 in 1961-62; they have been followed up to age 48 in nine repeated face-to-face interviews and up to age 56 in criminal records. Information was also collected in annual interviews with parents conducted by Study social workers when the boys were aged 8-14, from peer ratings at ages 8 and 10, and from teacher ratings at ages $8,10,12$, and 14 . At age $48,93 \%$ of the males who were still alive were interviewed (365 out of 394 ), and $42 \%$ of the males were convicted up to age 56 (170 out of 404 searched, excluding seven males who emigrated before age 21 and were not searched; see Farrington et al., 2013). Convictions were only counted for the more serious offenses normally recorded in the Criminal Record Office, excluding motoring offenses.

This article investigates the extent to which variables measured at age $8-10$ predicted youthful convictions between ages 10 and 18; for more information about all the age 8-10 variables, see West and Farrington (1973) and Farrington, Ttofi, and Coid (2009b). Up to age 18, 27\% (111) of 409 boys at risk were convicted. Many variables that were measured at age 8-10 were based on social worker ratings and were originally coded in three or four categories. In previous analyses focusing on risk factors for offending, these variables were often dichotomized into the "worst" quarter versus the 
remainder. In order to investigate risk and promotive effects in the present article, all age 8-10 variables were divided into the "worst" quarter (the risk end), the middle half, and the "best" quarter (the promotive end). Some age 8-10 variables could not be included in this analysis because they were originally measured as dichotomous variables, notably a convicted parent, a delinquent sibling, and poor housing (rated by social workers, identifying dilapidated slum housing). However, it was possible to trichotomize 24 important variables in six categories (shown in Table 1).

\section{Measures}

Nonverbal intelligence was measured using Raven's Progressive Matrices test, while verbal intelligence was based on verbal comprehension and vocabulary tests. School attainment was derived from school records of English, arithmetic, and verbal reasoning tests. Daring was based on peer and parent ratings of taking many risks in traffic, climbing, exploring, and so on. Poor concentration and restlessness in class (hyperactivity) were rated by the boy's teachers, and impulsiveness (psychomotor clumsiness) was measured using the Porteus Maze, Spiral Maze, and Tapping tests. Extraversion and neuroticism were measured using the New Junior Maudsley Inventory. Sample items were "I like to tell my friends all about things that happen to me" (trueextraversion) and "It takes a lot to make me lose my temper" (false-neuroticism). Nervousness was based on parent ratings of nervous-withdrawn boys, and the number of friends of the boy was also derived from questions to parents. Popularity and dishonesty were measured using peer ratings, while troublesomeness (gets into trouble most) was based on both peer and teacher ratings.

Family income was derived from information given by parents to social workers. Similarly, the social workers enquired about the number of children in the family (including full biological siblings of the boy) and about the job of the family breadwinner (usually the father). The socioeconomic status of this job was rated on the Registrar General's scale, 
ranging from professional and managerial to unskilled manual jobs. Delinquency rates of the schools were obtained from the local education authority. The age of the mother referred to her age at the time of her first birth, which was ascertained by the social workers. The nervousness of the mother was based on social worker ratings and also on records of her psychiatric treatment. The job of the mother was classified as full-time, part-time, or no job, and parental interest in the boy's education was rated by the social workers (based on their interviews with the parents).

Maternal and paternal discipline reflected warm or cold parental attitudes as well as harsh or erratic discipline. Parental harmony identified parents who were in conflict, and child-rearing was a variable that combined maternal and paternal discipline and parental harmony. Parental supervision measured whether the parents knew where the boy was when he was out, and parental separation identified boys who had been separated from a parent (usually the father) for at least three months for reasons other than death or hospitalization. All these variables were rated by the Study social workers and based on interviews with the parents (usually the mother).

The "best" and "worst" categories are usually obvious. However, for number of friends, the "best" category was having few or no friends, because of the previous finding that boys from criminogenic backgrounds who did not become delinquents tended to have few or no friends at age 8 (Farrington, Gallagher, Morley, St Ledger, \& West, 1988). Not hanging around with local boys in the neighborhood seemed to be a promotive and protective factor. For nervousness of the boy, the "best" category was being nervouswithdrawn, because of prior research suggesting that this variable was negatively related to offending (West \& Farrington, 1973, p.115). However, for neuroticism, the "worst" category was high neuroticism, because the neuroticism items referred to irritability and getting angry as well as nervousness. As mentioned, neuroticism measured emotional instability versus stability (calm, even-tempered children). For the age of the mother at the 
time of her first birth, being a teenager was the "worst" category. For the job of the mother, having a full-time job was the "best" category, having a part-time job was the middle category, and having no job was the "worst" category. Previous research in the Cambridge Study (e.g., West \& Farrington, 1973, p.209) showed that having full-time working mothers tended to predict low rates of delinquency among boys, possibly because (in this sample) these mothers were more intelligent and competent and tended to have fewer children.

The current study

The present analyses are based on and extend previous analyses that were carried out on the CSDD. Farrington and Ttofi (2011) previously investigated the extent to which trichotomized variables at age 8-10 predicted convictions up to age 50 . They found that most variables had primarily risk effects, with a large increase in the percent convicted in the "worst" category. A few variables (including extraversion, neuroticism, and number of friends) had primarily promotive effects, with a large decrease in the percent convicted in the "best" category (low extraversion, low neuroticism, and few friends, respectively). The remaining variables were either linearly related or not related to offending.

Farrington and Ttofi (2011) then investigated protective factors that predicted a low percent convicted among troublesome boys, and found that the most important were low daring, good parental supervision, small family size, and high nonverbal intelligence. Only good supervision was clearly an interactive protective factor; $38 \%$ of well supervised troublesome boys were convicted, similar to the $30 \%$ of nontroublesome boys who were convicted, and much lower than the $65 \%$ of more poorly supervised troublesome boys who were convicted.

Farrington and Ttofi (2011) also investigated protective factors that predicted a low percent convicted among boys in poor housing, and found that the most important were good child-rearing, small family size, low dishonesty, and low troublesomeness. Good 
child-rearing and small family size were clearly interactive protective factors. Compared with $32 \%$ of boys in better housing who were convicted, $33 \%$ of boys in poor housing and receiving good child-rearing were convicted, in contrast to $66 \%$ of those who received poorer child-rearing; and similarly $33 \%$ of boys in poor housing from small families were convicted, compared with $64 \%$ of those who came from larger families. The present article reports similar analyses for the prediction of delinquency (convictions between ages 10 and 18).

\section{Results}

\section{Risk and promotive factors}

Table 1 shows the percent convicted in each of the three categories of each variable. For example, $16 \%$ of 89 boys with low neuroticism were convicted, compared with $29 \%$ of 190 boys with medium neuroticism, and $32 \%$ of 116 boys with high neuroticism. Each variable is classified as a risk factor, a promotive factor, or mixed (linearly related to offending). The promotive odds ratio (OR) compares the promotive ("best") category with the remainder, while the risk OR compares the risk ("worst") category with the remainder. For neuroticism, the promotive OR was 2.3 (95\% confidence interval or $\mathrm{Cl}=1.3$ to 4.4$)$, while the risk $\mathrm{OR}$ was $1.4(\mathrm{Cl}=0.9$ to 2.2$)$. Therefore, neuroticism was considered to be a promotive factor. About half of the trichotomized variables (13 out of 24 ) seemed to be linearly related to offending. Of the rest, seven (nonverbal intelligence, impulsiveness, family income, social class, nervousness of

mother, child-rearing, and separation from a parent) had mainly risk effects, while four (neuroticism, nervousness of the boy, number of friends, job of mother) had mainly promotive effects.

\section{Table 1 about here}

The Cochran-Armitage linear trend test (Agresti, 1990, pp. 100-102) indicated that the percent convicted increased nonlinearly for family income (chi-squared $=2.81, p=$ 
.094 , two-tailed) and social class (chi-squared $=2.89, p=.089$, two-tailed). Neither effect was quite significant at $p=.05$ (two-tailed), but this test requires a marked deviation from linearity to obtain a significant effect. The percentages convicted were sometimes quite different: for example, $20 \%$ of boys from comfortable income families, $24 \%$ of boys from average income families, and $43 \%$ of boys from low income families. Similarly, the percentages convicted were $27 \%$ of boys from the highest social class families (with fathers in nonmanual or skilled manual occupations), $22 \%$ of boys from medium social class families (with fathers in semi-skilled manual occupations), and $35 \%$ of boys from low social class families (with fathers in unskilled manual occupations; where a father was unemployed, his last occupation was rated).

\section{Protective factors for troublesome boys}

In order to investigate risk-based protective factors, it is necessary to identify a reasonably large risk group. Table 1 shows that, comparing the "worst" quarter with the remainder, troublesomeness was the strongest age 8-10 predictor of youthful offending: $53 \%$ of the 91 most troublesome boys were convicted, compared with $20 \%$ of the remaining $318(\mathrm{OR}=4.5, \mathrm{Cl}=2.8$ to 7.4$)$. The next most important age $8-10$ dichotomous risk factors were a convicted parent $(O R=4.4)$, high daring $(O R=4.3)$, a delinquent sibling $(O R=3.1)$, a high delinquency-rate school $(O R=3.1)$, large family size $(O R=2.9)$, high dishonesty $(O R=2.9)$, poor parental supervision $(O R=2.8)$, low school attainment $(\mathrm{OR}=2.7)$, low family income $(\mathrm{OR}=2.6)$, and poor child-rearing $(\mathrm{OR}=2.5)$.

Initially, the plan was to identify protective factors that predicted a low probability of conviction among the most troublesome boys. However, few of these boys possessed potentially important protective factors such as high nonverbal intelligence (only $11 \%$ ), high verbal intelligence (10\%), high school attainment (7\%), low daring (10\%), or attending a low delinquency-rate school (13\%). Therefore, in order to overcome the problem of small numbers, it was decided to identify protective factors that predicted a low probability 
of conviction among boys in the two highest categories of troublesomeness. Troublesomeness was coded in four categories; $53 \%$ of the 91 most troublesome boys were convicted, compared with $40 \%$ of the 67 medium high boys, $22 \%$ of the 108 medium low boys, and $8 \%$ of the 143 least troublesome boys.

Risk-based protective factors were therefore studied among the most troublesome 158 boys, of whom $47 \%$ were convicted, and compared with the remaining 251 boys, of whom $14 \%$ were convicted. The key question was whether any protective factor would reduce the percent convicted among the most troublesome boys to somewhere near the $14 \%$ rate of the less troublesome boys.

Table 2 shows the percent convicted of troublesome and nontroublesome boys in the protective ("best") and nonprotective ("rest") categories. For example, among the troublesome boys, $26 \%$ of those who received good supervision were convicted, compared with $52 \%$ of the remaining boys $(\mathrm{OR}=3.2, \mathrm{Cl}=1.4$ to 7.4$)$.

\section{Table 2 about here}

The variables in Table 2 are ordered according to the (increasing) percent of troublesome boys in the protective category who were convicted. All seven variables were considered to be risk-based protective factors, because each was associated with a decrease in the percent of troublesome boys convicted of at least $10 \%$ (from $47 \%$ to $37 \%$ or less), and because all ORs were substantial (at least 1.7).

The job of the mother was the clearest example of an interactive protective factor, because it reduced the percent delinquent among troublesome boys but not among nontroublesome boys. The "best" category was the mother having a full-time job. The interaction effect was significant in an analysis of variance $(F=6.93, p=.009)$.

Protective factors for boys with a convicted parent

After troublesomeness, the next most important risk factor for youthful offending was having a convicted parent: 55 of the 109 boys with a convicted parent were 
themselves convicted, compared with 56 of the remaining 300 (50\% compared with 19\%: $\mathrm{OR}=4.4, \mathrm{Cl}=2.8$ to 7.1$)$. The question again is whether any risk-based protective factor could reduce the percent convicted among those with a convicted parent to somewhere near the $19 \%$ rate of those with nonconvicted parents.

Table 3 again orders the variables according to the percent of boys with a convicted parent in the protective category who were convicted. Twelve variables had protective effects, since they reduced the percent convicted by at least $10 \%$ (from $50 \%$ to $40 \%$ or less) and had substantial ORs (at least 2.0). Low dishonesty and high family income were the most important protective factors.

\section{Table 3 about here}

High family income and good child-rearing were interactive protective factors. As shown in Table 3, they reduced the percent convicted among boys with a convicted parent, but had no effect on the percent convicted among boys with nonconvicted parents. The interaction terms in analyses of variance were significant for high family income $(F=$ $9.21, p=.003)$ and good child-rearing $(F=4.18, p=.042)$.

Protective factors versus risk factors

Following the logic of Tables 2 and 3 , the extent to which each variable acted as a protective factor for each risk category was investigated. Table 1 shows that 21 variables were significant risk factors for youthful convictions. Risk-based and interactive protective factors for the two most important risk factors (high troublesomeness and a convicted parent) were investigated in Tables 2 and 3 . Of the other 19 significant risk factors, nine could not be studied because a risk category containing between about 120 and 200 boys could not be identified. For example, 93 boys were in low income families, 193 boys were in average income families, and 125 boys were in comfortable income families. A risk category of 93 was too few for this analysis, because of small numbers of boys in the risk group who were in a protective category. However, a risk category of $286(70 \%$ of the 
sample) was too many.

The 10 risk categories that could be studied were low nonverbal intelligence, low school attainment, high daring, high hyperactivity, high dishonesty, poor housing, large family size, nervous mother, poor child-rearing, and separation from a parent. Table 4 shows all statistically significant ORs obtained from relating protective factors to convictions in risk categories. For example, among the more hyperactive boys, only $3 \%$ of those with low troublesomeness were convicted, compared with $40 \%$ of the remainder $(\mathrm{OR}=21.1, \mathrm{Cl}=2.8$ to 158.1$)$. Thus, it could be argued that low troublesomeness acted as a protective factor against high hyperactivity. The hyperactive boys who were not troublesome were rarely convicted. The relationship between troublesomeness and convictions was much stronger among hyperactive boys than among all boys $(O R=4.5$ in Table 1).

\section{Table 4 about here}

There is not space here to discuss all the results in detail. Table 4 basically shows the most important examples of where a protective category combined with a risk category predicts an unusually low percentage of delinquents. Putting together Tables 2, 3, and 4, there were 279 tests of protective effects, and 93 (33\%) were significant, far in excess of the chance expectation of $5 \%$. In Table 4 , the most important risk-based protective factors were as follows: high verbal intelligence and high school attainment protected against poor child-rearing; low daring protected against poor child-rearing and high nervousness of the mother; low troublesomeness protected against high hyperactivity, low nonverbal intelligence, large family size, low school attainment, and separation from a parent; small family size protected against low nonverbal intelligence; high parental interest in education protected against poor child-rearing, separation from a parent, high daring, and poor housing; and good parental supervision protected against high hyperactivity, high dishonesty, and high nervousness of the mother. 
Interactive protective effects

All the 93 significant protective effects were tested to see if they involved significant interactive protective effects. As shown in Table 5, there were 22 significant interaction effects $(24 \%)$, again far in excess of the chance expectation of $5 \%$. Table 5 shows all of these, together with three near-significant interaction effects. In almost all cases, the significant interaction occurred because the protective factor reduced the percent convicted in the risk category and had no effect on the percent convicted in the non-risk category.

\section{Table 5 about here}

For example, of 184 boys who experienced relatively poor child-rearing, only $13 \%$ of 45 with high nonverbal intelligence were convicted, compared with $40 \%$ of 139 less intelligent boys $(\mathrm{OR}=4.4, \mathrm{Cl}=1.7$ to 11.0$)$. High nonverbal intelligence considerably reduced the risk of conviction among these boys (see Figure 2). Of 210 boys who experienced relatively good child-rearing, the percentage convicted did not vary significantly according to whether or not they had high nonverbal intelligence $(O R=0.7, \mathrm{Cl}$ $=0.3$ to 1.4$)$. This interaction effect was significant $(F=11.48, p<.001)$.

\section{Figure 2 about here}

Other important interaction effects were: good parental supervision protected against high dishonesty; high parental interest in education protected against poor childrearing; high family income protected against a criminal parent; high verbal intelligence and high school attainment protected against poor child-rearing; small family size and low troublesomeness protected against low nonverbal intelligence; and low daring protected against poor child-rearing.

\section{Conclusions}

In this article, we have used a number of conceptual definitions which we hope are useful in bringing clarity to the topic of protective factors. First, we defined a promotive 
factor as a variable that predicts a low probability of offending in the "best" category. In discussing promotive factors, we have sometimes used the variable name (e.g., intelligence) and sometimes focused on the "best" category (e.g., high intelligence). If a variable has a low probability of offending in the "best" category and a high probability of offending in the "worst" (risk) category, we have termed it a "mixed" risk and promotive factor. If a variable has a low probability of offending in the "best" category, but there is no increase in offending in the "worst" category, we have termed it a "pure" promotive factor.

Second, we defined a risk-based protective factor as a variable that predicts a low probability of offending among children at risk. Third, we defined an interactive protective factor as a variable that predicts a low probability of offending among children at risk but not among other children. The clearest example of an interactive protective factor is a variable that reduces the probability of offending among children at risk to the same rate as for those who are not at risk. It is rare for researchers to investigate interaction effects, but it is clearly important to do this in studying protective factors.

The present research has many strengths but also some weaknesses. The small sample size sometimes made it difficult to study protective factors, and there were relatively few significant results. All the age 8-10 variables were measured many years ago, when social conditions in South London were very different (e.g., there were very few single-parent families, few working mothers, few ethnic minorities, and a lot of dilapidated slum housing). It is important to investigate the extent to which the present results might be replicated in more recent longitudinal surveys in diverse settings with diverse populations. Systematic reviews are required to establish which individual, family, peer, school, and neighborhood factors interact with which other individual, family, peer, school, and neighborhood factors in preventing delinquency. Also, it is important to investigate the extent to which these results might be replicated using different methods (e.g., using continuous rather than trichotomized variables), where possible. The present methods 
are simple and understandable but need to be extended in multivariate analyses.

In the early 1960's when the Cambridge Study began, much was known about risk factors for offending, and one of the original aims of this project was to investigate the relative importance of these risk factors. Big efforts were made to measure the key risk factors for offending with the highest possible degree of accuracy and objectivity, and with the lowest possible subjectivity and bias (see West, 1969; West \& Farrington, 1973). Therefore, it is perhaps not surprising that most of the variables measured at age $8-10$ had risk effects or mixed effects in predicting offending. Little was known at that time, or even now, about promotive factors that predict a low probability of offending, and few researchers have investigated nonlinear relationships.

Nevertheless, the present analyses have revealed numerous promotive, risk-based protective, and interactive protective factors. These results are important for theory, policy, and practice. For example, developmental and life-course theories (see e.g. Farrington \& Ttofi, 2015) generally focus on main effects of risk factors especially, and tend to ignore promotive effects, risk-based protective factors, and interactive protective factors. These theories need to be extended to explain the present results. The findings on interactive protective factors suggest particular types of interventions that should be targeted on particular types of people who exhibit specific risk factors. The results of intervention experiments could help to determine which relationships were causal. For example, since good parental supervision tends to nullify the risk factor of high dishonesty, a clear implication is that parent training methods should be targeted on the parents of dishonest boys. As another example, since high parental interest in education tends to nullify the risk factor of poor child-rearing, efforts should be made to identify parents with poor child-rearing and improve their interest in their children's education. Taken together, these findings underscore the critical nature of effective parental socialization early in the life course (see e.g., Piquero et al., 2009). However, because the current methods are 
innovative and the results are original, they need to be replicated in other prospective longitudinal studies of delinquency.

\section{Acknowledgements}

For funding the Cambridge Study in Delinquent Development, we are very grateful to the Home Office, the Department of Health, the Department for Education, the Rayne Foundation, the Barrow Cadbury Trust, and the Smith-Richardson Foundation. 


\section{References}

Agresti, A. (1990). Categorical data analysis. New York: Wiley.

Baglivio, M.T., Jackowski, K., Greenwald, M.A., \& Howell, J.C. (2014). Serious, violent, and chronic juvenile offenders: A statewide analysis of prevalence and prediction of subsequent recidivism using risk and protective factors. Criminology and Public Policy, 13, 83-116.

Cohen, P. (1996). Childhood risks for young adult symptoms of personality disorder: Method and substance. Multivariate Behavioral Research, 31, 121-148.

Farrington, D. P. (1988). Studying changes within individuals: The causes of offending. In M. Rutter (Ed.), Studies of psychosocial risk: The power of longitudinal data (pp. 158-183). Cambridge, UK: Cambridge University Press.

Farrington, D. P. (2000). Explaining and preventing crime: The globalization of knowledge -- The American Society of Criminology 1999 Presidential Address. Criminology, $38,1-24$.

Farrington, D. P., Coid, J. W., Harnett, L., Jolliffe, D., Soteriou, N., Turner, R., \& West, D. J. (2006). Criminal Careers up to age 50 and life success up to age 48: New findings from the Cambridge Study in Delinquent Development. London: Home Office (Research Study No. 299).

Farrington, D. P., Coid, J. W., \& West, D. J. (2009a). The development of offending from age 8 to age 50: Recent results from the Cambridge Study in Delinquent Development. Monatsschrift fur Kriminologie und Strafrechtsreform (Journal of Criminology and Penal Reform), 92, 160-173.

Farrington, D. P., Gallagher, B., Morley, L., St Ledger, R. J., \& West, D. J. (1988). Are there any successful men from criminogenic backgrounds? Psychiatry, 51, 116130.

Farrington, D. P. \& Loeber, R. (2000). Some benefits of dichotomization in psychiatric and criminological research. Criminal Behaviour and Mental Health, 10, 100-122.

Farrington, D. P., Loeber, R., Yin, Y., \& Anderson, S. J. (2002). Are within-individual causes of delinquency the same as between-individual causes? Criminal Behaviour and Mental Health, 12, 53-68.

Farrington, D. P., Piquero, A. R., \& Jennings, W. G. (2013). Offending from childhood to late middle age: Recent results from the Cambridge Study in Delinquent Development. New York: Springer.

Farrington, D. P. \& Ttofi, M. M. (2011). Protective and promotive factors in the development of offending. In T. Bliesener, A. Beelman, \& M. Stemmler (Eds.), Antisocial behavior and crime: Contributions of developmental and evaluation research to prevention and intervention (pp. 71-88). Cambridge, MA: Hogrefe.

Farrington, D. P. \& Ttofi, M. M. (2015). Developmental and life-course theories of 
offending. In J. Morizot \& L. Kazemian (Eds.), The development of criminal and antisocial behavior: Theory, research, and practical applications (pp. 19-38). New York: Springer.

Farrington, D. P., Ttofi, M. M., \& Coid, J. W. (2009b). Development of adolescencelimited, late-onset and persistent offenders from age 8 to age 48 . Aggressive Behavior, 35, 150-163.

Hawkins, J. D., \& Catalano, R. F. (1992). Communities That Care: Action for drug abuse prevention. San Francisco, CA: Jossey-Bass.

Kazdin, A. E., Kraemer, H. C., Kessler, R. C., Kupfer, D. J., \& Offord, D. R. (1997). Contributions of risk-factor research to developmental psychopathology. Clinical Psychology Review, 17, 375-406.

Kraemer, H. C., Kazdin, A. E., Offord, D. R., Kessler, R. C., Jensen, P. S., \& Kupfer, D. J. (1997). Coming to terms with the terms of risk. Archives of General Psychiatry, 54, 337-343.

Loeber, R. \& Farrington, D. P. (Eds.) (1998). Serious and violent juvenile offenders: Risk factors and successful interventions. Thousand Oaks, CA: Sage.

Loeber, R., Farrington, D. P., Stouthamer-Loeber, M., \& White, H. R. (2008). Violence and serious theft: Development and prediction from childhood to adulthood. New York: Routledge.

Piquero, A.R., Farrington, D.P., \& Blumstein, A. (2007). Key issues in criminal career research: New analyses of the Cambridge Study in Delinquent Development. Cambridge, UK: Cambridge University Press.

Piquero, A.R., Farrington, D.P., Welsh, B.C., Tremblay, R., \& Jennings, W. (2009). Effects of early family/parent training programs on antisocial behavior and delinquency. Journal of Experimental Criminology, 5, 83-120.

Pollard, J. A., Hawkins, J. D., \& Arthur, M. W. (1999). Risk and protection: Are both necesssary to understand diverse behavioral outcomes in adolescence?" Social Work Research, 23, 145-158.

Rutter, M. (1985). Resilience in the face of adversity: Protective factors and resistance to psychiatric disorder. British Journal of Psychiatry, 147, 598-611.

Sameroff, A. J., Bartko, W. T., Baldwin, A., Baldwin, C., \& Seifer, R. (1998). Family and social influences on the development of child competence. In M. Lewis \& C. Feiring (Eds.), Families, risk, and competence (pp. 161-185). Mahwah, NJ: Lawrence Erlbaum.

Werner, E. E., \& Smith, R. S. (1982). Vulnerable but invincible: A study of resilient children. New York: McGraw-Hill.

West, D. J. (1969). Present conduct and future delinquency. London: Heinemann. 
West, D. J. \& Farrington, D. P. (1973). Who becomes delinquent? London: Heinemann.

White, J. L., Moffitt, T. E., \& Silva, P.A. (1989). A prospective replication of the protective effects of IQ in subjects at high risk for delinquency. Journal of Consulting and Clinical Psychology, 37, 719-724. 
Table 1

Risk and Promotive Factors for Youthful Convictions

\begin{tabular}{|c|c|c|c|c|c|c|}
\hline \multirow[t]{2}{*}{ Variable at age 8-10 } & \multicolumn{3}{|c|}{$\%$ Convicted } & \multicolumn{2}{|c|}{ Odds Ratio } & \multirow[t]{2}{*}{ Type } \\
\hline & Prom & Mid & Risk & Prom & Risk & \\
\hline Attainment & & & & & & \\
\hline Nonverbal Intelligence & 20 & 25 & 39 & $1.7^{*}$ & $2.1^{*}$ & Risk \\
\hline Verbal Intelligence & 16 & 28 & 37 & $2.4^{*}$ & $1.8^{*}$ & Mixed \\
\hline School attainment & 13 & 27 & 43 & $3.1^{*}$ & $2.7^{*}$ & Mixed \\
\hline \multicolumn{7}{|l|}{ Self-control } \\
\hline Daring & 13 & 21 & 49 & $3.1^{*}$ & $4.3^{*}$ & Mixed \\
\hline Hyperactivity & 20 & 29 & 42 & $2.1^{*}$ & $2.3^{*}$ & Mixed \\
\hline Impulsiveness & 22 & 25 & 37 & 1.4 & $1.9^{*}$ & Risk \\
\hline Extraversion & 20 & 27 & 31 & 1.6 & 1.3 & Mixed \\
\hline Neuroticism & 16 & 29 & 32 & $2.3^{*}$ & 1.4 & Prom \\
\hline \multicolumn{7}{|l|}{ Personality } \\
\hline Nervousness & 20 & 29 & 28 & 1.6 & 1.1 & Prom \\
\hline Popularity & 21 & 26 & 33 & 1.6 & $1.7^{\star}$ & Mixed \\
\hline Number of friends & 15 & 28 & 28 & 2.1 & 1.2 & Prom \\
\hline Dishonesty & 12 & 26 & 43 & $3.6^{*}$ & $2.9^{*}$ & Mixed \\
\hline Troublesomeness & 8 & 29 & 53 & $6.5^{\star}$ & $4.5^{\star}$ & Mixed \\
\hline \multicolumn{7}{|l|}{ Socioeconomic } \\
\hline Family income & 20 & 24 & 43 & $1.7^{*}$ & $2.6^{*}$ & Risk \\
\hline Social class & 27 & 22 & 35 & 1.1 & 1.6 & Risk \\
\hline Housing & -- & 21 & 38 & -- & $2.3^{*}$ & -- \\
\hline Family size & 18 & 25 & 44 & $2.2^{*}$ & $2.9^{*}$ & Mixed \\
\hline School delinquency rate & 16 & 28 & 48 & $2.7^{*}$ & $3.1^{*}$ & Mixed \\
\hline \multicolumn{7}{|l|}{ Parent } \\
\hline Convicted parent & -- & 19 & 50 & -- & $4.4^{*}$ & -- \\
\hline Age of mother & 17 & 28 & 38 & $2.1^{*}$ & $1.9^{*}$ & Mixed \\
\hline Nervousness of mother & 21 & 22 & 36 & 1.5 & $2.1^{*}$ & Risk \\
\hline Job of mother & 21 & 29 & 28 & 1.5 & 1.1 & Prom \\
\hline Interest in education & 15 & 30 & 41 & $2.8^{*}$ & $2.3^{*}$ & Mixed \\
\hline \multicolumn{7}{|l|}{ Family } \\
\hline Delinquent sibling & -- & 24 & 50 & -- & $3.1^{*}$ & -- \\
\hline Child-rearing & 19 & 24 & 41 & $1.8^{*}$ & $2.5^{\star}$ & Risk \\
\hline Supervision & 16 & 25 & 44 & $2.2^{*}$ & $2.8^{*}$ & Mixed \\
\hline Separations & 23 & 24 & 41 & $1.7^{*}$ & $2.3^{*}$ & Risk \\
\hline
\end{tabular}

Notes: $\quad$ Prom $=$ Promotive, Mid $=$ Middle.

Odds Ratio: compares promotive category with rest, or risk category with rest.

${ }^{*} \mathrm{p}<$.05, two-tailed 
Table 2

Protective Factors for Troublesome Boys

\begin{tabular}{|l|c|c|c|c|c|c|}
\hline \multicolumn{1}{|c|}{ Variable at age 8-10 } & \multicolumn{3}{c|}{ \% Convicted } & \multicolumn{3}{c|}{ \% Convicted } \\
NT (14)
\end{tabular}

Notes: $T=$ Troublesome, NT $=$ Nontroublesome.

$\mathrm{P}=$ Protective category, NP $=$ Nonprotective category .

${ }^{*} \mathrm{p}<$.05, two-tailed

Significant interaction for job of mother: $F=6.93, p=.009$

Table 3

Protective Factors for Boys with Convicted Parents

\begin{tabular}{|l|c|c|c|c|c|c|}
\hline \multicolumn{1}{|c|}{ Variable at age 8-10 } & \multicolumn{3}{c|}{ \% Convicted C (50) } & \multicolumn{3}{c|}{ \% Convicted NC (19) } \\
\hline & P & NP & OR & P & NP & OR \\
\hline Dishonesty & 23 & 58 & $4.7^{*}$ & 10 & 22 & $2.5^{*}$ \\
Family income & 26 & 59 & $4.0^{*}$ & 18 & 19 & 1.0 \\
Troublesomeness & 30 & 55 & $2.9^{*}$ & 5 & 28 & $7.7^{*}$ \\
Interest in education & 30 & 54 & $2.7^{*}$ & 11 & 22 & $2.3^{*}$ \\
Child-rearing & 30 & 55 & $2.8^{*}$ & 17 & 18 & 1.1 \\
Nonverbal Intelligence & 33 & 53 & 2.2 & 18 & 19 & 1.1 \\
Neuroticism & 33 & 57 & 2.7 & 12 & 20 & 1.8 \\
No. of friends & 33 & 52 & 2.2 & 6 & 19 & $3.4^{*}$ \\
School attainment & 35 & 54 & 2.2 & 9 & 23 & $3.0^{*}$ \\
Job of mother & 35 & 54 & 2.2 & 17 & 18 & 1.1 \\
Family size & 35 & 56 & $2.4^{*}$ & 13 & 22 & 1.9 \\
Verbal Intelligence & 36 & 53 & 2.0 & 13 & 21 & 1.9 \\
\hline
\end{tabular}

Notes: $\mathrm{C}=$ Convicted parent, $\mathrm{NC}=$ Nonconvicted parent.

$\mathrm{P}=$ Protective category, NP = Nonprotective category.

${ }^{*} \mathrm{p}<.05$, two-tailed

Significant interactions for family income $(F=9.21, p=.003)$ and child-rearing $(F=4.18, p=$ 0.42). 
Table 4

Protective Factors versus Risk Factors

\begin{tabular}{|c|c|c|c|c|c|c|c|c|c|c|}
\hline Protective & & & & & iisk F & actors & & & & \\
\hline & NI & SA & DAR & HYP & DIS & HOU & FS & NM & CR & SEP \\
\hline Attainment & & & & & & & & & & \\
\hline High nonverbal intelligence & $\mathrm{X}$ & & & & & & 3.6 & & 4.4 & \\
\hline High verbal intelligence & & & & 3.6 & & & & 3.2 & 6.0 & 3.8 \\
\hline High school attainment & & $\mathrm{X}$ & & & & & 3.4 & 3.4 & 8.4 & 3.4 \\
\hline Self-regulation & & & & & & & & & & \\
\hline Low daring & 2.6 & 2.4 & $\mathrm{x}$ & 2.6 & 3.5 & & 3.4 & 5.8 & 6.6 & \\
\hline Low hyperactivity & 2.0 & & & $\mathrm{X}$ & 2.1 & & 2.5 & & 2.1 & \\
\hline Low extraversion & & 3.3 & & 2.5 & & & 3.1 & & & \\
\hline Low neuroticism & 2.4 & & & & 2.5 & & 3.3 & & & 3.0 \\
\hline Personality & & & & & & & & & & \\
\hline High nervousness & & & 3.5 & & & & & & 2.1 & \\
\hline $\begin{array}{l}\text { Few friends } \\
\text { Low dishonesty }\end{array}$ & 3.0 & $\begin{array}{l}3.5 \\
2.6\end{array}$ & & 3.9 & $x$ & & & 4.2 & 3.1 & \\
\hline Low troublesomeness & 14.7 & 9.0 & & 21.1 & 5.1 & 2.9 & 10.6 & 7.0 & 6.4 & 8.4 \\
\hline $\begin{array}{l}\text { Socioeconomic } \\
\text { High family income }\end{array}$ & & & & & & & & & & \\
\hline Small family size & 3.8 & 2.1 & & 2.4 & & 3.2 & $\mathrm{X}$ & 3.3 & 3.0 & 2.7 \\
\hline Low school delinquency & 2.6 & 3.0 & & 2.9 & & & 2.3 & 2.5 & 3.5 & 3.1 \\
\hline Parent & & & & & & & & & & \\
\hline Older mother & 2.4 & 2.4 & & 2.3 & & & & & 3.3 & \\
\hline Low nervous mother & & 2.3 & & 2.2 & & & & $\mathrm{X}$ & & \\
\hline $\begin{array}{l}\text { Full-time job of mother } \\
\text { High interest in education }\end{array}$ & 3.0 & 2.4 & 3.8 & & & 3.5 & 2.6 & 3.0 & $\begin{array}{l}2.4 \\
7.9\end{array}$ & 5.3 \\
\hline $\begin{array}{l}\text { Family } \\
\text { Good child-rearing } \\
\text { Good supervision } \\
\text { Not separated }\end{array}$ & $\begin{array}{l}2.8 \\
1.9\end{array}$ & 2.4 & & 4.1 & 5.0 & 3.0 & 2.5 & 5.2 & $\begin{array}{c}X \\
3.7\end{array}$ & $\begin{array}{r}2.3 \\
\mathrm{X}\end{array}$ \\
\hline
\end{tabular}

Notes: Odds Ratios are shown (all $p<.05$, two-tailed).

$\mathrm{NI}=$ Low nonverbal intelligence, $\mathrm{SA}=$ Low school attainment, DAR $=$ High daring,

$\mathrm{HYP}=$ High hyperactivity, DIS = High dishonesty, $\mathrm{HOU}=$ Poor housing, FS =Large family size,

$\mathrm{NM}=$ High nervousness of mother, $\mathrm{CR}=$ poor child-rearing, SEP = Separated.

No significant results for high impulsiveness, low popularity, or low social class. 
Table 5

Significant Interaction Effects

\begin{tabular}{|c|c|c|c|c|c|c|c|c|c|}
\hline \multirow[t]{2}{*}{$\begin{array}{l}\text { Risk } \\
\text { Factor }\end{array}$} & \multirow[t]{2}{*}{$\begin{array}{l}\text { Protective } \\
\text { Factor }\end{array}$} & \multicolumn{3}{|c|}{$\begin{array}{c}\% \text { Convicted in } \\
\text { Risk }\end{array}$} & \multicolumn{3}{|c|}{$\begin{array}{l}\% \text { Convicted in } \\
\text { Non-Risk }\end{array}$} & \multicolumn{2}{|c|}{$\begin{array}{c}\text { Interaction } \\
\text { Test }\end{array}$} \\
\hline & & $\mathbf{P}$ & NP & OR & $\mathbf{P}$ & NP & OR & $\mathbf{F}$ & $p$ \\
\hline Poor child-rearing & High nonverbal IQ & 13 & 40 & $4.4^{*}$ & 25 & 18 & 0.7 & 11.48 & .001 \\
\hline High dishonesty & Good supervision & 14 & 45 & $5.0^{*}$ & 18 & 14 & 0.7 & 10.98 & .001 \\
\hline Poor child-rearing & High interest education & 9 & 42 & $7.9^{*}$ & 18 & 22 & 1.3 & 9.72 & .002 \\
\hline Convicted parent & High family income & 26 & 59 & $4.0^{*}$ & 18 & 19 & 1.0 & 9.21 & .003 \\
\hline Poor child-rearing & High verbal IQ & 11 & 42 & $6.0^{*}$ & 19 & 21 & 1.1 & 8.75 & .003 \\
\hline Poor child-rearing & High school attainment & 8 & 40 & $8.4^{*}$ & 18 & 22 & 1.3 & 8.11 & .005 \\
\hline Low nonverbal IQ & Small family size & 16 & 42 & $3.8^{*}$ & 19 & 21 & 1.1 & 7.11 & .008 \\
\hline Low nonverbal IQ & Low troublesomeness & 5 & 46 & $14.7^{*}$ & 10 & 27 & $3.3^{*}$ & 7.11 & .008 \\
\hline Poor child-rearing & Low daring & 10 & 43 & $6.6^{*}$ & 15 & 22 & 1.6 & 7.07 & .008 \\
\hline High troublesomeness & Full-time job of mother & 31 & 53 & $2.5^{*}$ & 16 & 13 & 0.8 & 6.93 & .009 \\
\hline High daring & High nervousness & 24 & 52 & $3.5^{*}$ & 19 & 18 & 0.9 & 6.69 & .010 \\
\hline Large family size & High nonverbal IQ & 17 & 43 & $3.6^{*}$ & 20 & 19 & 0.9 & 5.70 & .017 \\
\hline Low nonverbal IQ & Good child-rearing & 20 & 41 & $2.8^{*}$ & 19 & 18 & 1.0 & 5.49 & .020 \\
\hline Large family size & Low extraversion & 21 & 44 & $3.1^{*}$ & 20 & 19 & 0.9 & 5.24 & .023 \\
\hline Low school Attainment & Low extraversion & 16 & 38 & $3.3^{*}$ & 22 & 19 & 0.8 & 5.06 & .025 \\
\hline Low school Attainment & Low nervous mother & 21 & 38 & $2.3^{*}$ & 23 & 17 & 0.7 & 5.05 & .025 \\
\hline High hyperactivity & Good supervision & 13 & 38 & $4.1^{*}$ & 20 & 21 & 1.1 & 4.99 & .026 \\
\hline Poor housing & Good child-rearing & 21 & 45 & $3.0^{*}$ & 18 & 20 & 1.2 & 4.92 & .027 \\
\hline High nervous mother & Good supervision & 13 & 44 & $5.2^{*}$ & 16 & 23 & 1.5 & 4.89 & .028 \\
\hline Poor child-rearing & Full-time job of mother & 20 & 38 & $2.4^{*}$ & 22 & 19 & 0.8 & 4.42 & .036 \\
\hline Large family size & High family income & 23 & 44 & $2.6^{*}$ & 19 & 19 & 1.0 & 4.19 & .041 \\
\hline Convicted parent & Good child-rearing & 30 & 55 & $2.8^{*}$ & 17 & 18 & 1.1 & 4.18 & .042 \\
\hline Large family size & Good child-rearing & 24 & 44 & $2.5^{*}$ & 17 & 18 & 1.1 & 3.79 & .052 \\
\hline Poor child-rearing & Older mother & 17 & 40 & $3.3^{*}$ & 16 & 21 & 1.4 & 3.62 & .058 \\
\hline Low school attainment & Full-time job of mother & 19 & 36 & $2.4^{*}$ & 20 & 18 & 0.9 & 3.51 & .062 \\
\hline
\end{tabular}

Note: ${ }^{*} \mathrm{p}<.05$, two tailed. $\mathrm{P}=$ Protective category, $\mathrm{NP}=$ Nonprotective category, $\mathrm{OR}=$ Odds Ratio 
Figure 1: Prediction of violence in early adulthood from variables in early adolescence

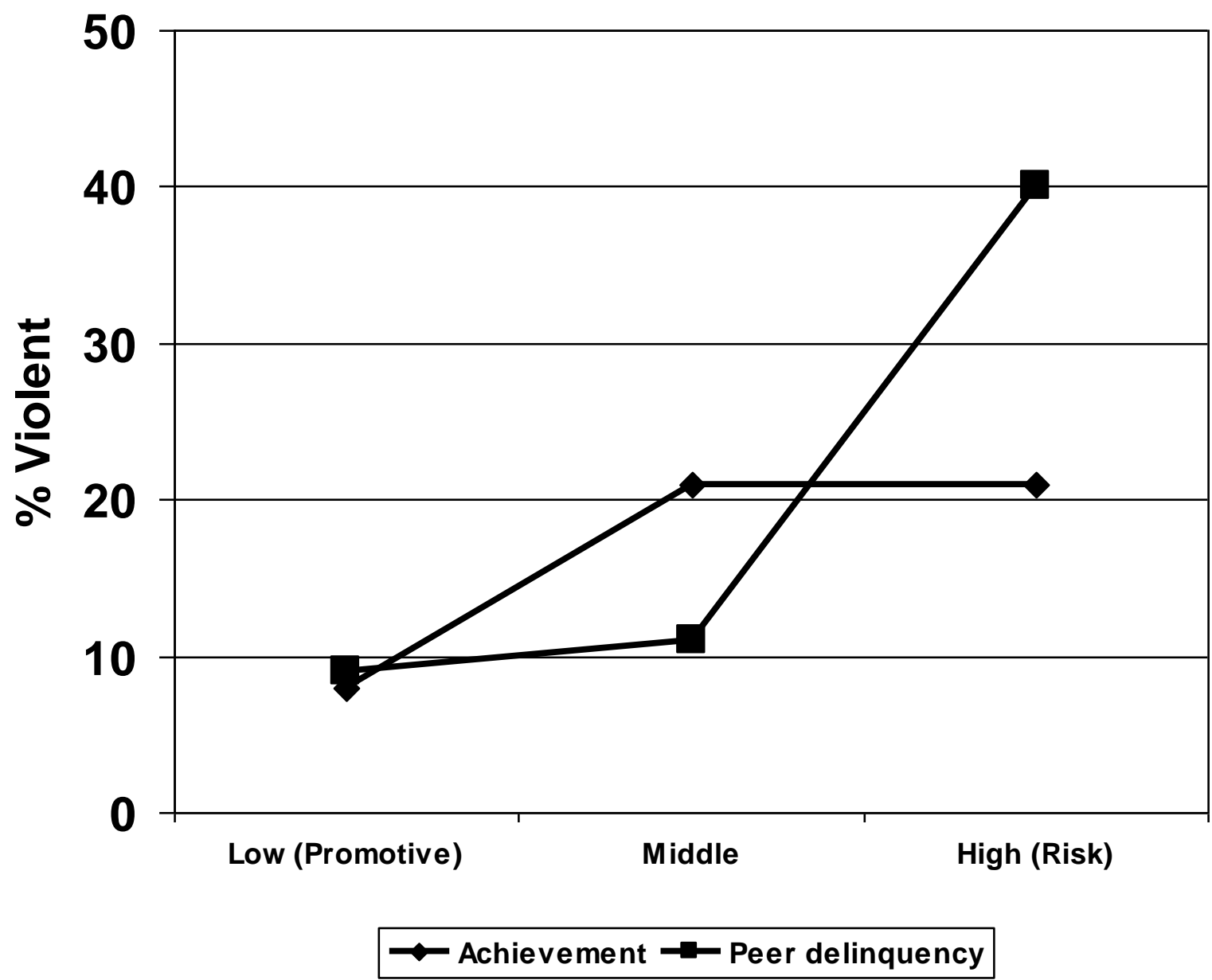


Figure 2. Percent Convicted Versus Child Rearing and Nonverbal Intelligence

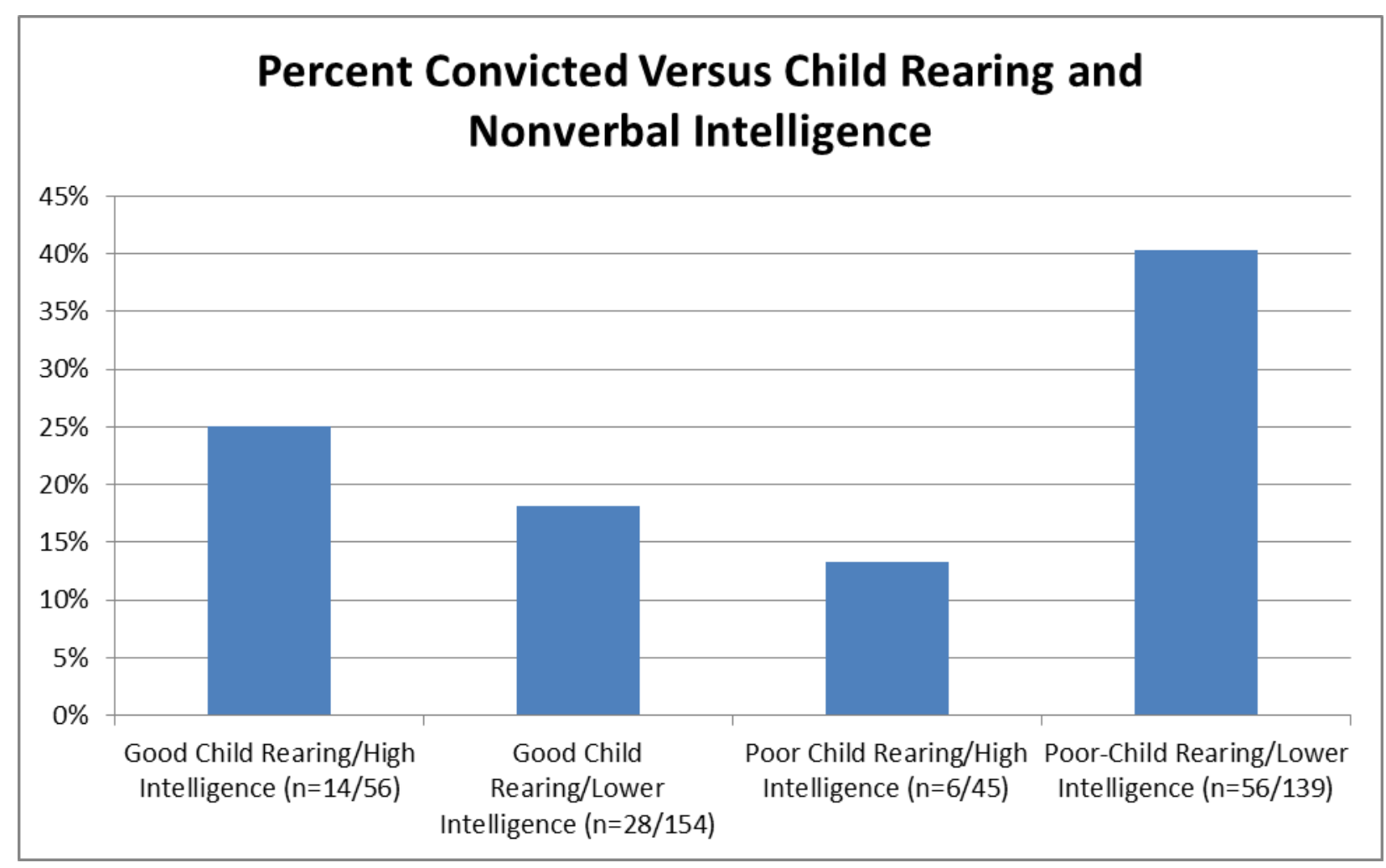

